\title{
University of Applied Sciences Students' Engagement with Scientific Literature for Final Year Projects: An Exploratory Study
}

\author{
Abdul Rauf*, Hanna Rahma Abdelwahab, \\ Dadi Chen and Peter Birdsall \\ Wittenborg University of Applied Sciences, Apeldoorn, The Netherlands \\ https:/ / orcid.org/0000-0003-4269-7275 \\ https://orcid.org/0000-0002-3059-8088 \\ https:/ / orcid.org/0000-0001-9797-7309 \\ https://orcid.org/0000-0001-9903-5358
}

\begin{abstract}
Students at universities of applied sciences (UAS) tend to overlook the importance of using scientific literature in their final year projects (FYP), which could affect the quality of their research. This paper explores how UAS students use scientific publications and theories/research frameworks for empirical research in their FYPs. Data were collected from 1) questionnaire completed by 31 final-year and recently graduated students, and 31 academic supervisors and Research Methods teachers, and 2) evaluation of 18 FYPs in an international UAS in the Netherlands. The samples were randomly selected from the university's formal database (i.e., sampling frame). The analysis of the data led to the discovery of some key factors, such as lack of knowledge in selecting literature, inability to conduct an effective literature review and inability to develop a suitable conceptual/theoretical framework, which hindered the engagement of UAS students with scientific literature. Students' lack of knowledge in conducting a literature review limited the quality of their final year projects and they need specialized workshops to develop their skills in literature research and critical analysis.
\end{abstract}

Keywords: Final Year Project (FYP); scientific inquiry; student research; scientific literature review

*Corresponding author: Rauf, A., rauf.abdul@wittenborg.eu 


\section{Introduction}

With their increasing involvement in European research and innovation programs, Dutch Universities of Applied Sciences (UAS), which deliver higher education in the Netherlands, are creating a greater impact on knowledge society and economy. The improvement of the quality of research is becoming more important than before among the UASs (Vereniging Hogescholen, 2019). The requirements, such as understanding and application of knowledge in solving problems, and the ability to gather and interpret data, are prescribed by the Dublin Descriptors, which are used to define the graduation level of higher professional education study programs in the Netherlands and other member states in the EU (Bologna Working Group, 2005; Vereniging Hogescholen, 2019). The final year projects (FYP) of university students are commonly seen as the culmination of their learning experiences and the quality of this output often serves to assess the quality of the program as a whole (Jawitz et al., 2002). As per the guidelines of the European Higher Education Area (EHEA), the FYP has to be a project leading to cutting-edge research, resulting in innovation in the relevant field (Tuononen \& Parpala, 2021). This is a challenge in many UASs as fundamentally UASs students were not required to complete an academic FYP.

One of the challenges for students is the use of scientific literature in their FYPs (Sodhar et al., 2020). Badenhorst (2018) described a literature review as a complex, demanding, challenging, and overwhelming task and states later that "literature reviews are a genre that many graduate students do not fully grasp and find difficult to write" (p. 263). The engagement and review of scientific literature involves searching/selecting academic sources, interpreting critically, extracting from manuscripts, and synthesizing into a comprehensive chapter based on the specific research goals. This meticulous process involving multiple steps requires a good level of competency and research skills for an effective scientific academic discourse (Carracedo et al., 2018). Chen et al. (2016) explained that recent research on FYP literature reviews focuses more on linguistic and methodological issues, neglecting key conceptual and ontological aspects. An important pedagogy aspect missing here relates to the engagement with cutting-edge scientific literature from academic sources on the selected FYP topic.

At the selected UAS based in the Netherlands, one of the objectives of its integrated business and management curriculum is to expand the scientific research skills of the internationally diverse student body and to identify a variety of opportunities that will allow them to experience scientific applied research. This is achieved through core mandatory research modules in the final year of studies both in bachelor's and master's programs. After the taught modules, students must complete a substantive FYP, which comprises a written submission of their work together with an oral defense in front of the graduation committee. One of the objectives of the Research Methods module in this UAS is to engage students in learning how to use scientific literature. However, although students are guided by their supervisors in rationalizing their FYPs by scientific literature, the graduation committee still found most FYPs fall short in sufficient guidance on how to conduct critical literature reviews. 
Accreditation requirements and industry needs demand recent program and curriculum developments at the institutional level, which involve more engagement with scientific literature and research frameworks/models in students' FYPs to see their contributions in connection with academic research. Drafting a critical literature review for the FYP appears to be one of the most complicated writing tasks for both graduate and undergraduate students.

The goal of the current study is to investigate the possible difficulties students face in engaging with scientific literature in their FYPs with a focus on the reasons, the extent of the issue, and how they can be dealt with. These are pertinent towards ensuring quality of study programs at UASs and their research contributions to the wider scientific community in applied research. The following research questions guided this study:

1) What difficulties do students face in conducting FYP research grounded in relevant scientific literature?

2) What techniques do students use when applying scientific literature to ground academic research in a proper scientific context?

\section{Literature review}

\subsection{Importance of literature reviews for student's FYPs}

It is important to note that the subject/topic of this study is a scientific literature review so we will mainly be discussing this subject under this section, which is unusual compared to other studies on traditional business/management topics. The literature review of a research study serves the purpose of presenting the author/authors' knowledge about the topic under investigation and includes key concepts, ideas, theories, and previous relevant research to set any new research on proper footing (Juntunen \& Lehenkari, 2021). A literature review is fundamental in establishing the basis of an academic inquiry. Advancing knowledge/understanding on any particular subject begins with existing authentic literature. The theoretical framework and the literature review are intrinsically linked and often the former is used as a guide to logically develop the latter (Grant \& Osanloo, 2015). The underlying functions of a literature review have been identified to note the current knowledge about a subject of inquiry, identifying knowledge gaps for future research, critically appraising and synthesizing what is known of the subject and comparatively analyzing to solve an identified research problem, or adding new knowledge to the existing body of knowledge on the topic of research investigation (Cuozzo et al. 2017). The importance of a literature review in an academic study is summed up by Snyder (2019), who stated that it is not merely descriptive summaries of research conducted between certain years, but a deeper analysis of those studies and "provides a new theory or includes a well-grounded substantial research agenda or propositions on which other researchers can build to advance the field" ( $p$. 339).

Understanding the main goals of a literature review is pertinent to useful research results/findings and it clarifies the researchers' focus in relation to searching for, selecting, analyzing relevant literature sources, and drafting the 
literature review. Various studies have identified some challenges in this regard, indicating that many FYPs fail to interpret the relevant extant literature and/or provide researchers' critical perspective on the information given - rather, it looks more like a list of known facts (Shahsavar \& Kourepaz, 2020). For example, Walter and Stouck (2020) highlighted that "graduate students face linguistic, methodological, conceptual, and, importantly, ontological challenges when writing their literature reviews" (p. 1). Other studies discussed some of the mistakes students commit when reviewing literature. Examples of such mistakes include failing to report the search procedure, failing to define the best descriptors in identifying sources and relate the findings of the literature review to one's own study, giving uncritical acceptance of another researcher's findings and interpretations as valid and reporting isolated statistical results rather than synthesizing them by quantitative statistical analysis, such as the chi-squared test (Hart, 2018; Snyder, 2019; Kraus, Breier, \& Dasi-Rodriguez, 2020; Fisch \& Block, 2018). In addition to the above issues mentioned, Snyder (2019) added that researchers often lack details on how the analysis of articles was conducted and tend to limit the search or pare the sample size to make the review manageable. Limiting the sample by limiting the number of journals, using a narrow year span, or excluding articles from related fields affect both the depth and rigor of the review, which can in effect have a serious impact on the results and contributions of the whole research.

A quality literature review should be the appropriate breadth and depth with extensive analysis and synthesis, preferably based on relevant scientific literature to justify the selected research topic, selection of research methods, and rationale of conducting the proposed study (Fisch \& Block, 2018). The breadth and depth of the review depends on the type of literature research, and it is up to the discretion of the researchers investigating for a particular topic. The next section will look at the process of conducting a critical literature review and the reasons why following a systematic process can add value to academic research including FYPs.

\subsection{The critical literature review process for guiding, analyzing and executing FYPs}

It is important to carry out a comprehensive search of relevant and extant scientific literature when conducting academic research. The literature review acts as a knowledge map in advancing our understanding and knowledge for theory building and uncovers novel research areas. Many researchers have presented detailed recommendations to guide FYP students and researchers on how to conduct a literature review (e.g., Aguinis et al., 2018; Booth et al., 2016; Fisch \& Block, 2018; Kraus et al., 2020; Xiao \& Watson, 2019). Based on an extensive review of 92 peer-reviewed articles on literature review methodology, Xiao and Watson (2019) recommended that all reviews be conducted by following eight common steps: (1) formulating the research problem, (2) developing and validating the review protocol, (3) searching the literature, (4) screening for inclusion, (5) assessing quality, (6) extracting data, (7) analyzing and synthesizing data, and (8) reporting the findings. These steps could be grouped into three main steps for producing a critical literature review on a 
given research topic, e.g. (1) searching, (2) reading/interpreting/analyzing and synthesizing arguments/concepts/theories in the relevant literature and (3) drafting and presenting ideas clearly and systematically to guide the research investigation (Kraus et al., 2020; Hart, 2018).

\subsubsection{Searching relevant literature}

A literature search should be systematic, explicit, thorough and rigorous. According to Mok et al. (2015), searching for relevant literature involves four stages: the initial search, filtering, visual examination and content analysis. Keywords are often used during the initial search process in relevant scientific research databases, journals and digital/online libraries. Filtering refers to the process whereby sources found in the initial stage are included or excluded for further analysis of the searched literature. Setting up clear exclusion and inclusion criteria can provide the researchers with a transparent data collection and synthesis. This will enhance the objectivity and reproducibility of the research work (Kraus et al., 2020). Visual examination requires the researcher to scan the content of the selected literature sources and screen them to identify the ones which are not relevant to the critical analysis. The final selection/collection of literature sources after the third stage will form the possible pool of relevant literature and will go through the last stage of content analysis. Adopting the above model with necessary adjustment can help students during their FYP research in filtering unnecessary and irrelevant literature in an efficient way with minimal effort.

Another important aspect to consider when undertaking a literature search is the type of literature sources. Using relevant peer-reviewed scientific journals is encouraged as the process of review ensures that a consistently high standard of material is published. Wide collection of information from primary sources (e.g., empirical studies and statistical reports) and tertiary sources (e.g., government and official publications or reports) can support the research with authentic and verified facts, while secondary sources of unverified information can negatively affect the quality of a critical literature review (Roberts-Holmes, 2018; Walter \& Stouck, 2020).

\subsubsection{Reading, interpreting, analyzing and synthesizing literature}

A literature review needs structure in order to flow and avoid becoming an aimless description of unlinked theories, concepts, definitions or ideas (Badenhorst, 2018). A large number of students appear to struggle in synthesizing prior research on their FYP research topics and/or appear to find difficulties understanding how any available theoretical framework can assist them in conducting theoretical/empirical studies (Shahsavar \& Kourepaz, 2020). Cronin, Ryan and Coughlan (2008) caution that the review should not be just a description of a series of studies but instead should include a critical but objective evaluation of the literature. As Norton (2019) wrote, "an academic degree requires students to have independent thinking rather than faithfully reproducing others' views" (p.21). A study conducted by Komba (2015) among postgraduate students in Tanzania, for example, revealed that more than $65 \%$ of the theses and dissertations surveyed failed to: 
- Present theoretical backgrounds

- Present critical literature reviews, e.g.

- loose and uncritical argumentation

- lack of synthesis

- failure to identify areas of controversy

- Derive knowledge gaps

- Produce quality write-up in terms of English language competency

Such findings underline the importance of our study and what students need to keep in mind while conducting a critical literature review for FYPs.

\subsubsection{Drafting and presenting}

When it comes to drafting and presenting the literature review, some FYPs lack the necessary thoroughness and systematic reflection. A recent study revealed that most students were not able to synthesize, critique, or critically analyze the literature in their FYPs (Shahsavar \& Kourepaz, 2020). A critical literature review is intended to present the potential reconceptualization of the expanding and more diversified knowledge through a theoretical framework, which also simplifies the research through visualization of key research variables. The next section elucidates this in detail.

\subsection{Conceptual and theoretical frameworks in students' FYPs}

The process of undertaking academic research involves a series of iterative steps (Saunders et al., 2019; Birley \& Moreland, 2014; Robert-Holmes, 2018; Quinlan, 2011). For example, Quinlan (2011), developed the four-framework approach (conceptual, theoretical, methodological and analytical frameworks) for students as a guide to develop their FYPs. Conceptual and theoretical frameworks were used as the bases for our study while the remaining frameworks do not fall within the ambit of this investigation. The next section presents a critical reflection on conceptual and theoretical frameworks in the context of FYPs produced by university students.

\subsubsection{Conceptual framework in academic research}

Research built on relevant theories and conceptual frameworks has a solid basis for achieving success because it will help to advance knowledge on the topics/subjects in the research (Quinlan, 2011; Illing, 2017). A concept is a key word or idea which contains a great deal of meaning (Quinlan, 2011). The conceptual framework contains all the key concepts in a research project. These key concepts point to the contemporary/extant relevant literature to be reviewed by the student to answer the research questions effectively. Badenhorst (2018) suggested that the engagement of relevant scientific literature is significant to the success of any academic research, as it ensures feasibility to investigate the selected topic before the research actually begins. Some researchers suggest that any research conducted in an academic setting should be embedded in relevant theoretical discourse which possibly emerges from a conceptual framework in making a contribution to the theory in that field (Quinlan, 2011). Ravitch and Riggan (2017) suggested that novice researchers 
should spend considerable time at the outset of their research conceptualizing, identifying, and articulating the components of their conceptual framework.

\subsubsection{Theoretical framework used in academic research}

Emerging from the conceptual framework is the theoretical framework, or what is generally known as the scientific literature review design (Quinlan, 2011). A theoretical framework is usually constructed and designed by students from theory/theories relevant to the FYP to support the research and contains a discussion or review of the extant literature on the research subject. Such a theoretical conceptualization undergirds the students' thinking around the whole process of the research investigation. Considering this, developing an appropriate theoretical framework for scientific research is a significant process, because it requires all four constructs of research - i.e., the research problem, purpose, significance and research questions - to be precisely aligned and intricately interwoven so that a theoretical framework can guide the students in their research design and data analysis for their FYPs (Roberts-Holmes, 2018). Despite its significance in the research process, the theoretical framework is one aspect which is often overlooked by students in general, and hence minimally covered in their research work. Grant and Osanloo (2016) found that students often express uncertainty, a lack of understanding or knowledge, and frustration with the challenge of selecting a theoretical framework in order to properly apply it throughout the FYP.

Considering the above findings and reflection about the FYP literature review conducted by students, especially the systematic methods of literature research by Mok et al. (2015) and Shahsavar and Kourepaz (2020), there is a lack of research in Dutch higher education/private universities/UASs on the engagement with scientific literature in students' FYPs. The most important aspect is the lack of systematic evaluation methods and tools for critically evaluating the previous research to add new knowledge in different disciplines. There is a need to investigate these very aspects using a valid methodology, which is discussed next.

\section{Methodology}

\subsection{Research Design and Context}

This study used the exploratory sequential mixed method design, whereby a qualitative data collection and analysis were followed by quantitative data collection and analysis (Creswell, 2003). It included three parts as presented in Table 1 (Berman, 2017; Shahsavar \& Kourepaz, 2020). 
Table 1: Overview of the Research Methods, Instruments and Data (Own Conceptualization)

\begin{tabular}{|c|c|c|}
\hline Research methods & Research instruments & Data \\
\hline $\begin{array}{l}\text { Qualitative data } \\
\text { collection and analysis }\end{array}$ & $\begin{array}{l}\text { Semi-structured } \\
\text { questionnaire }\end{array}$ & $\begin{array}{l}\text { Answers from Research } \\
\text { Methods teachers and academic } \\
\text { supervisors in a UAS. }\end{array}$ \\
\hline \multirow[t]{2}{*}{$\begin{array}{l}\text { Quantitative data } \\
\text { collection and analysis }\end{array}$} & $\begin{array}{l}\text { Rubrics adapted from } \\
\text { Bootes and Bailey } \\
\text { (2005) and American } \\
\text { Public University } \\
\text { System rubric (n.d.) } \\
\text { guideline. }\end{array}$ & $\begin{array}{l}18 \text { FYPs: Twelve FYPs from a } \\
\text { bachelor's program, three from } \\
\text { an MSc program and three from } \\
\text { an MBA program in a UAS in } \\
\text { the Netherlands were selected } \\
\text { randomly. }\end{array}$ \\
\hline & $\begin{array}{l}\text { Structured } \\
\text { questionnaire }\end{array}$ & $\begin{array}{l}\text { Final-year students and recent } \\
\text { graduates from bachelor's and } \\
\text { master's program in a UAS. }\end{array}$ \\
\hline
\end{tabular}

\subsection{Participants}

The participants of the study included Research Method Teachers (RMTs), Academic Supervisors (ASs) and final-year or recently graduated bachelor's and master's students at a UAS in the Netherlands. All three groups of research participants were selected based on non-probability, purposive sampling and to ensure a representative number of respondents, a combination of heterogeneous sampling and volunteer sampling was chosen (Saunders et al., 2019). This UAS in the Netherlands was specially selected due to the ease of accessibility of data as the research population voluntarily accepted to participate in this research. Permissions were obtained from the UAS with the assurance of the anonymity of the participants and the name of the UAS.

\subsection{Research Instruments}

Semi-structured questionnaires were designed based on the literature review and previous studies on FYPs (Hart, 2018; Chen et al., 2016; Xiao \& Watson, 2019), and were administered separately for students, ASs and RMTs. The questions were developed by one of the researchers and then vetted by the coauthors to ensure the validity and reliability of the data collection instruments. The questionnaires consisted of two parts. Part I contained questions pertaining to the respondents' demographic information. Part II contained multiple-choice and open-ended questions related to the research focus for their FYP and the FYP research. The questionnaires were first pilot-tested on four final-year students and two AS/RMTs who did not form part of the final sample in the study.

In addition to the primary data collected, an archival analysis was also conducted on a sample of FYPs. A total of 18 completed FYPs were randomly selected from the secure online library database of the UAS between the years 2018 and 2020. A validated rubric by Bootes and Beile (2005) and the American Public University System iRubric (n.d.) were adapted by the researchers to evaluate the FYPs. Bootes and Beile (2005) created a five-category rubric to evaluate the effectiveness of a literature review in an academic study. The 
categories are coverage, synthesis, methodology, significance and rhetoric. The iRubric contains seven components linked with three categories, namely Evaluation of Literature Review, Evaluation of Reference Materials, and Evaluation of Conceptual or Theoretical Framework. The specific details of this rubric used for FYP analysis including results as per our analysis (Table 2).

\subsection{Data Collection and analysis}

Emails including links to the online questionnaires were sent to the participants explaining the purpose of the research. Participation in the survey was voluntary and it was made clear that all names were anonymized, and the participants could opt out any time during the survey.

In this exploratory study, the sequential mixed method design was applied. In the quantitative part, questionnaires from 31 final-year or recently graduated students (21 final-year and 10 recently graduated students, split equally between master's and bachelor's programs), 27 ASs, and four RMTs were analyzed. For the qualitative part, open coding was conducted using grounded theory, and themes were extracted from the data itself (Saunders, Lewis, \& Thornhill, 2019; Izadinia, 2014). Inferential analysis was then used to analyze significant differences between the different groups' responses (Malechwanzi et al., 2016). Non-parametric techniques were employed as the Likert type data are ordinal in nature. Using the method developed by Braun and Clarke (2006), thematic analysis was used to transcribe verbal data, generating initial codes, searching for themes, reviewing themes, defining and naming themes, and producing reports (Braun \& Clarke, 2006; Shahsavar \& Kourepaz, 2020).

\section{Results}

In this section, we report and discuss the main findings from the data analysis, e.g., perceptions of the RMTs, ASs and students on scientific literature in completed FYPs.

\subsection{Demographic background}

To start, the general demographic and background characteristics of the ASs and RMTs can be summarized as follows:

About $76 \%$ of the ASs and $100 \%$ of RMTs have been in the Education Service for 6 years or more. In addition, the majority of the ASs (43\%) have 6 or more years' experience as an AS; while half of the RMTs have more than 10 years' experience as an RMT, and the other half has between 1 to 5 years' experience.

\subsection{Perception of the academic supervisors (AS) and research methods teachers (RMT)}

4.2.1 Perception of FYP/RP on quality of FYPS

While $40 \%$ of ASs either strongly agreed or agreed that students submit good quality FYPs, a strong 56 \% neither agreed nor disagreed with it (Fig. 1). As for RMTs, a high percentage (75\%) disagreed that students submit good quality Research Proposals (RP) (Fig. 2). 


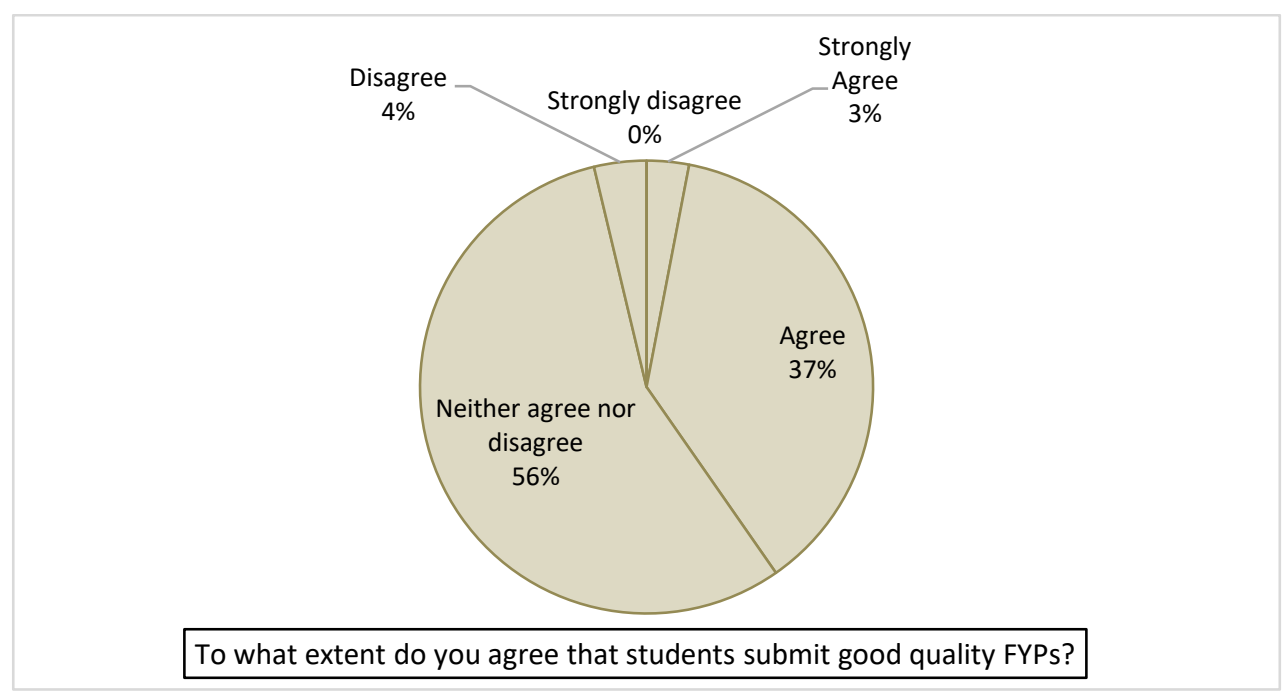

Figure 1: ASs' Perception of the Quality of Students' FYPs (Source: Authors)

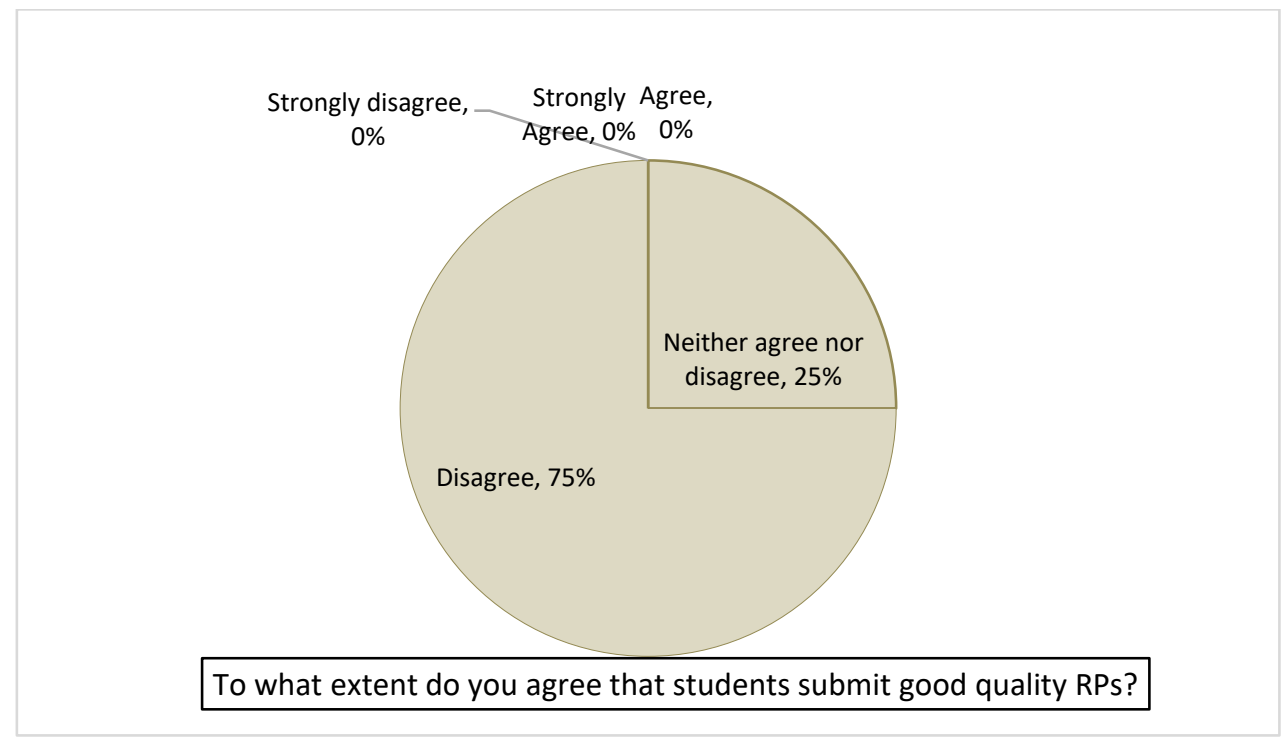

Figure 2: RMT's perception of the quality of students' RPs (Source: Authors)

Regarding whether students read relevant books/articles on how to carry out an academic research and write their FYPs or RPs, $48 \%$ of ASs agreed or strongly agreed with the statement, while 30 per cent did not have an opinion and $23 \%$ disagreed or strongly disagreed. For RMTs, $75 \%$ of them had no opinion while $25 \%$ disagreed that students with the statement. Both ASs and RMTs agreed that the top reason why students did not read relevant books/articles is because they do not think it was necessary.

According to the ASs, the top three challenges faced by students when doing their FYPs are: (1) searching for relevant questions and objectives, (2) finding the right topic, and (3) writing up a critical literature review (Table 2). This is somewhat in line with the RMTs' opinions, as they responded that the top three reasons why students failed their RPs were: (1) the topic was too wide and not 
focused, (2) the research objectives were not clear or too far-fetched and (3) the research questions were not correctly formulated.

Table 2: Ranking of Top 3 Challenges

\begin{tabular}{llll}
\hline Alternatives (No. of ASs who ranked) & $\mathbf{1}^{\text {st }}$ & 2nd & $\mathbf{3}^{\text {rd }}$ \\
\hline Finding the right topic & $33 \%$ & $22 \%$ & $11 \%$ \\
Searching for relevant questions and objectives & $44 \%$ & $37 \%$ & $4 \%$ \\
Writing up a critical literature review & $33 \%$ & $26 \%$ & $11 \%$ \\
Choosing the most suitable research methodology & $26 \%$ & $11 \%$ & $30 \%$ \\
Conducting an analysis on the findings & $11 \%$ & $33 \%$ & $19 \%$ \\
Writing conclusion and providing & $15 \%$ & $7 \%$ & $26 \%$ \\
recommendations & & & \\
\hline
\end{tabular}

On the question of whether students engaged relevant scientific literature in their FYPs, about $59 \%$ of ASs strongly agreed or agreed that they did, while $22 \%$ had no opinion and 19\% disagreed or strongly disagreed (Fig. 3).

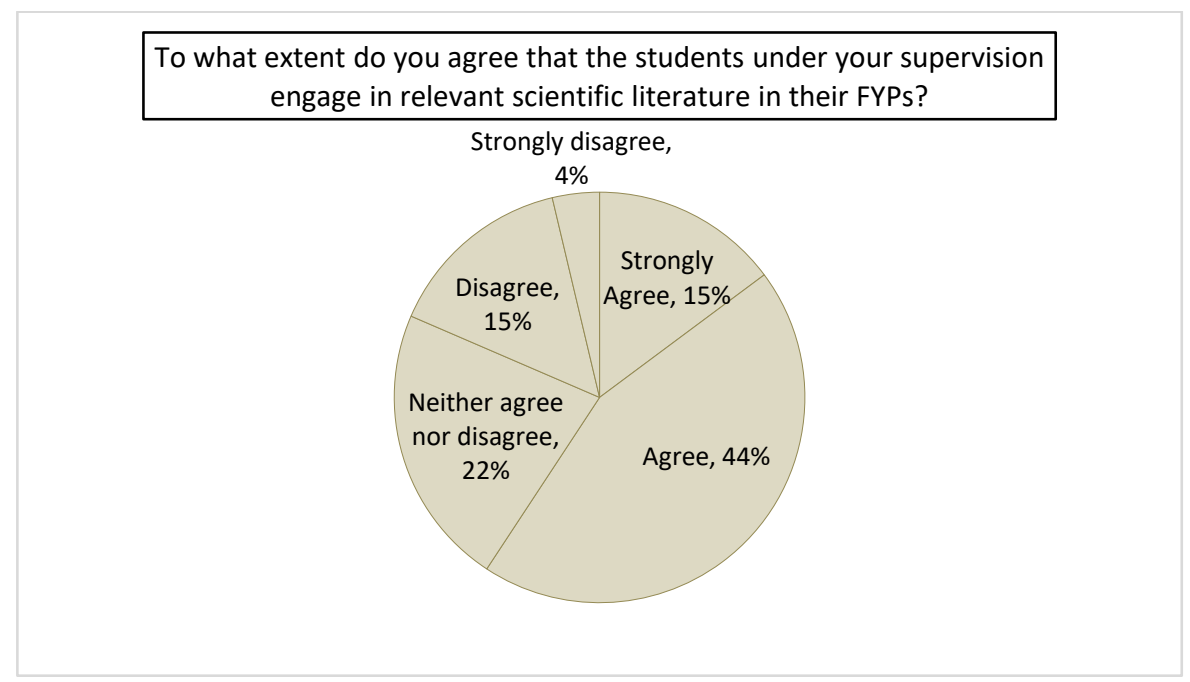

Figure 3: ASs' Perception of students' engagement in relevant scientific literature in their FYPs (Source: Authors)

With regard to searching for relevant references for their research, $41 \%$ of the ASs were not sure whether their students had employed systematic "search and selection strategies". Despite that, 11\% strongly agreed and 18\% agreed (total of $30 \%$ at least agreed) that they did employ some kind of systematic strategy, while 19\% disagreed or strongly disagreed (Fig. 4). Examples of "search and selection strategies" referred to above are: search using Google Scholar, search using keywords, search articles within time frame, use proper filtering and discarding, read the abstract, and scan through articles. 


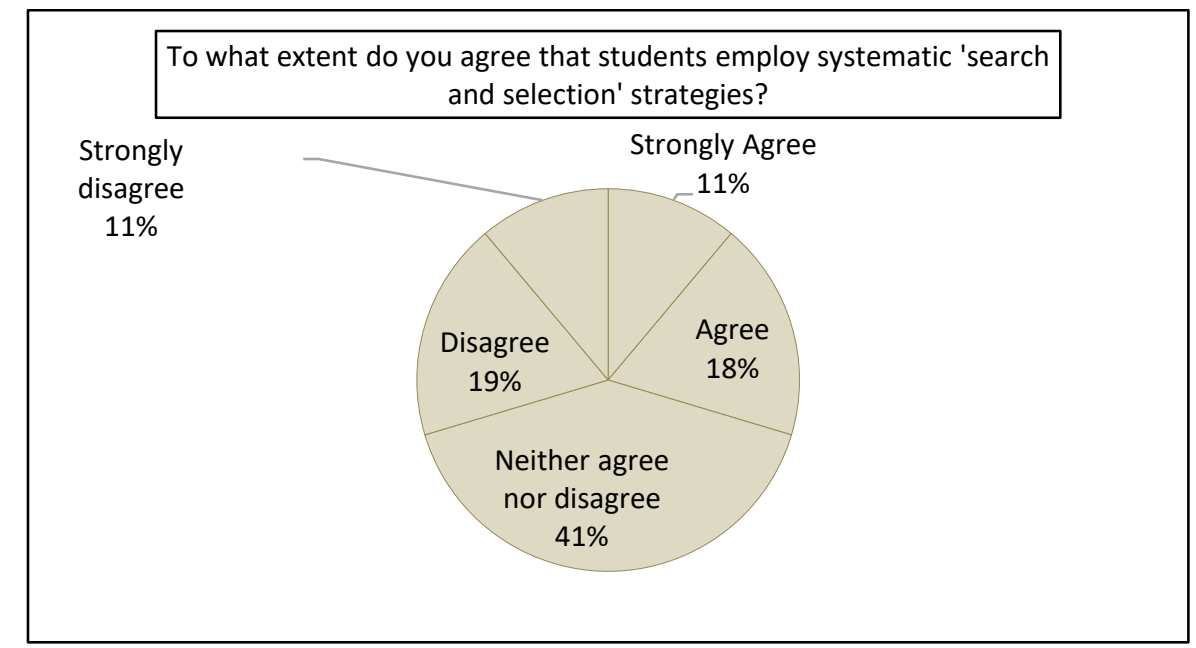

Figure 4: ASs' perception on whether students employ systematic 'search and selection strategies' (Source: Authors)

Thirty-seven percent of the ASs were not sure if their students knew how to conduct a critical literature review and another 30\% disagreed or strongly disagreed (Fig. 5). Such a high number reflects a negative perception ASs have of their students' capabilities. Despite this, ASs affirmed that students, in their literature reviews, analyzed articles based on themes, discussed related variables and phenomena related to the topic and mentioned previous research on their FYP topics. However, in their opinions, students failed to compare and contrast ideas related to their FYP topics (26\%) or analyze articles chronologically $(30 \%)$.

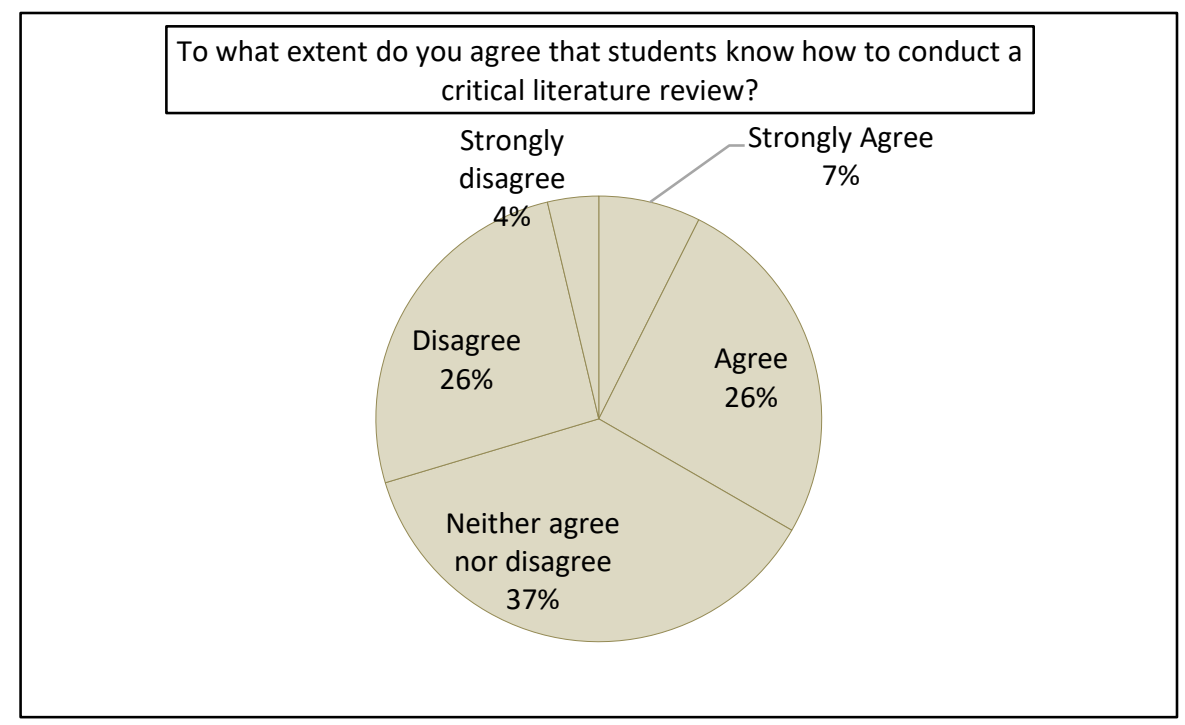

Figure 5: ASs' Perceptions on Students' Ability to Conduct Critical Literature Review (Source: Authors)

The majority of ASs (77\%) strongly agreed or agreed that the use of a conceptual/theoretical framework can enhance the quality of students' FYPs. Further, in relation to this, $63 \%$ of them agreed or strongly agreed that their students included it in their FYPs (Fig. 6). In their opinions, they believed that 
those students who had not included the conceptual/theoretical framework in their FYPs, probably did not know what it actually is or how to develop it.

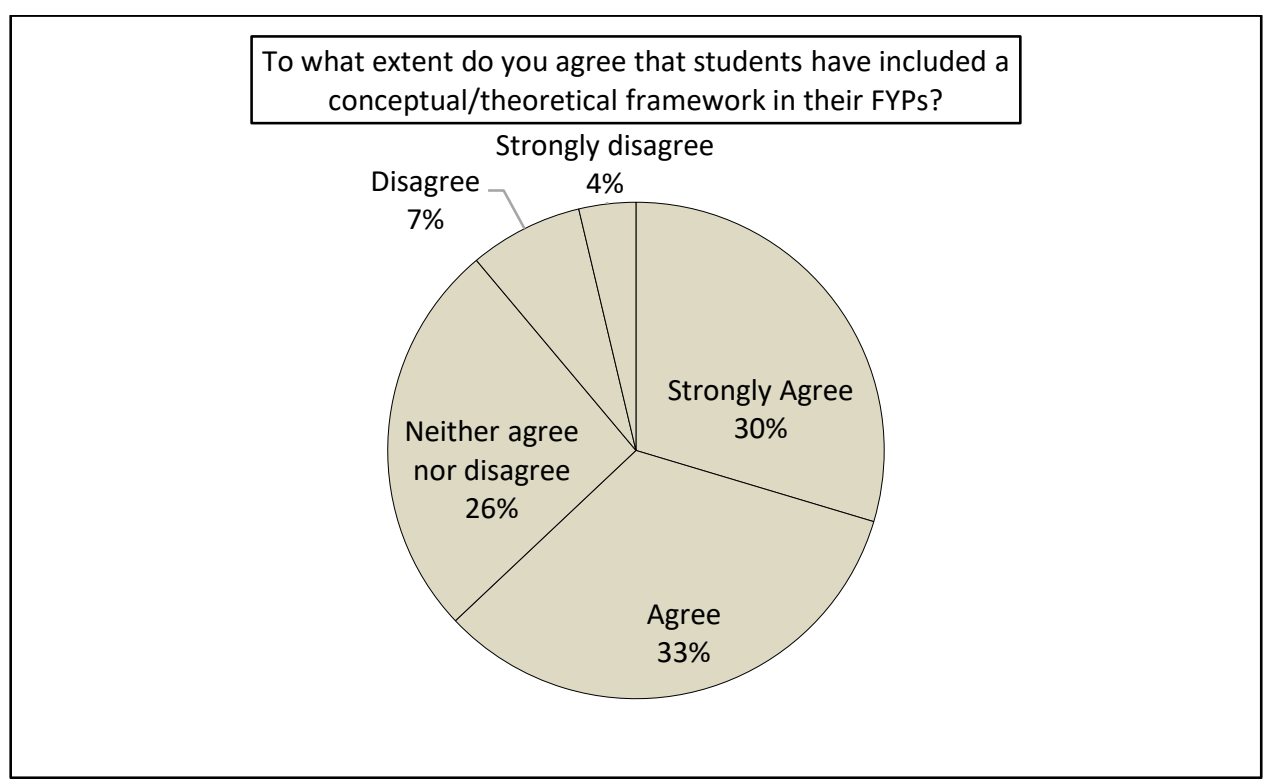

Figure 6: AS's Perceptions on whether students have included a conceptual/theoretical framework in their FYPs? (Source: Authors)

ASs and RMTs were also asked for their recommendations with regard to the following challenges faced by students in:

- conducting a critical literature review in their FYPs or RPs

- developing or adapting conceptual/theoretical framework in their FYPs or RPs

- how to increase students' engagement in scientific literature in their FYPs or RPs

The recommendations were analyzed and coded based on emerging themes. Three themes emerged from the analysis as follows:

1) Conduct mandatory workshops, seminars, or extra lessons in addition to RM classes to specifically teach students how to search for relevant literature; how to conduct an effective critical literature review; and how to develop or adapt a conceptual/theoretical framework.

2) Enforce compulsory reading assignments from various journal articles or theses on the above topics. ASs or RMTs can provide samples of good FYPs or articles that demonstrate how to compare, contrast, analyze and synthesize information or articles with good development or adaptation of conceptual/theoretical frameworks.

3) Enforce mandatory writing assignments, such as an annotated bibliography, or a critical review of an article.

A few ASs and RMTs commented that the majority of students know what a literature review entails but are not trained well enough or not sure what strategies to employ when choosing relevant literature. This leads to them using any literature available and merely mentioning studies in their literature review 
without properly analyzing or synthesizing the information. They also commented that students do not have enough training or practice on how to read literature critically; how to select the relevant information; and how to analyze them critically. What they [the students] manage to do is merely dumping information without adding value to the topic of their research. As one of the ASs commented:

"Practice the development of effective Annotated Bibliography. I offer my students a special one-hour class on the foundations of an effective Annotated Bibliography. Separate between the terms Literature Research and Literature Reviews. Students need to develop a research strategy using tools like mind mapping, Word Cloud as well as Zotero. Students should be able to gradually develop a sense of what constitutes a valuable academic source."

Another AS suggested: "1) apply marketing research techniques to research development and read, 2) constantly check elaboration of new arguments and embrace/consider arguments against his/her thesis proposal, and 3) welcome and gather constructive feedback constantly."

\subsection{Perceptions of students on scientific literature in their FYPs}

The findings from the questionnaire responses of the students gave more details about the challenges in using scientific literature in their FYPs. For example, 90\% of students acknowledged that relevant scientific/academic literature would help in increasing the quality of their FYPs and a majority of them had included peer-reviewed journal articles, books, as well as government/official publications in their FYPs, in addition to some other sources. The average number of scientific literature sources included in their FYPs was more than 20. About $58 \%$ of the students read relevant literature, e.g., books/articles on how to carry out research, but they only read a few chapters of the books or a few articles. This coincides with the opinions of ASs and RMTs that students do not really read in detail prior to carrying out their FYPs.

Furthermore, about $71 \%$ of the students included a conceptual/theoretical framework in their study. Most of them have adapted (modified) the conceptual/theoretical framework from existing frameworks because the existing frameworks fit their research needs well with minor modifications. For those who did not include the conceptual/theoretical framework in their FYPs, most of them gave the reason that it was not relevant to their research.

With regard to 'search and selection strategies', almost $90 \%$ of students searched for articles via Google Scholar and $71 \%$ read the abstract, but less than 50\% employed other strategies, such as searching using only keywords, searching within a certain timeframe, using proper filtering and discarding or scanning through articles. This is almost in line with the opinions of ASs, whereby only $30 \%$ affirmed that their students did employ such strategies in their FYPs. On average, more than $58 \%$ of students included the significance of the research problem, analysis of articles based on relevant themes, important variables and phenomena, subject vocabulary and compared and contrasted ideas related to the FYP topic in their Literature Review. This finding is supported by the similar findings for ASs, whereby the majority affirmed that their students did include 
the above components in their Literature Review. There is a discrepancy in opinion though, for compare and contrast of ideas related to the FYP topic. Only about $26 \%$ of ASs agreed that students managed to compare and contrast ideas related to the FYP topic but $58 \%$ of students claimed that they did.

In general, the majority of students faced challenges in the following three areas: formulating the research questions; writing up a critical literature review; and choosing the correct methodology. Students emphasized the difficulty of conducting a good literature review, as they were not sure how broad they should go or how to narrow down their research topics. Students gave several recommendations, among which they emphasized the importance of spending enough time on reading and summarizing literature; collecting sufficient amount of relevant literature; and using the literature to formulate research topics and structure the FYPs. One of them commented:

"Read, read, read! Make summaries or organize articles related to key words and topics. Write extensively and then narrow it down to make it more structured and analytical without forgetting things or having to read everything twice". Another wrote, "Do lot of literature reading and spend time developing it".

A few students recommended reading model or sample FYPs to help them get a head start, which is similar to what the ASs and RMTs advised. In helping to choose research topics, one student suggested:

"I would recommend reading lots of articles before choosing a research topic, because, in my opinion, the more articles you read the chances are higher that you can look for that specific gap for your topic, and if you somehow find it you can really go ahead with your topic."

\subsection{Evaluation of scientific literature in FYPs}

All FYPs examined in this study recorded more than 50 references and more than 30 scholarly articles from peer-reviewed journals (Table 3). This finding is supported by the students' questionnaires that reported the average number of scholarly articles they used is more than 20. All FYPs identified the significance of the research, important/relevant variables, vocabulary and phenomena, and provided good justifications for the selected methodologies and grounded on previous research. This was also supported by the findings from ASs and students' questionnaire.

However, by using the evaluation rubric, it is obvious that much needs to be improved for the use of scientific literature in students' FYPs. As shown in Table 2 , out of the 18 FYPs, only three showed criteria for search and selection of literature sources and inclusion and exclusion of articles/book chapters and other relevant academic literature sources. This result supports the ASs' perceptions, of which a majority of $41 \%$ neither agreed nor disagreed that there was some sort of strategies. 13 out of 18 FYPs failed to portray a coherent, clear structure of the analysis that supported the review of various literature. This proved what the ASs claimed that students failed to show a comparison and contrast of ideas from previous research to their own research topics. 
17 out of 18 FYPs presented a conceptual/theoretical framework. This is in line with the findings for ASs, whereby $75 \%$ reported that their students included a conceptual/theoretical framework in their FYPs. However, what was more evident from the analysis of the FYPs is that only eight clearly defined and linked the conceptual/theoretical framework to their own particular study. The remaining nine failed to clearly explain the theory on the selected research themes or situate the study in a larger/relevant theoretical context. One FYP did not even show any evidence of engaging with relevant theory or a theoretical framework.

Table 3: Analysis of FYPs (Source: Authors)

\begin{tabular}{|c|c|c|c|c|}
\hline Category & \multicolumn{2}{|l|}{ Criterion for evaluation of Literature Review } & Yes & No \\
\hline \multirow{2}{*}{ Coverage } & \multicolumn{2}{|l|}{ Justified criteria for selection of articles } & 3 & 15 \\
\hline & \multicolumn{2}{|c|}{ Justified criteria for inclusion and exclusion of articles } & 3 & 15 \\
\hline \multirow{3}{*}{ Synthesis } & \multicolumn{2}{|c|}{$\begin{array}{l}\text { Distinguished what has been done in the field and what } \\
\text { needs to be done }\end{array}$} & 18 & 0 \\
\hline & \multicolumn{2}{|c|}{ Articulated important variables and phenomena } & 18 & 0 \\
\hline & \multicolumn{2}{|l|}{ Acquired and enhanced the subject vocabulary } & 18 & 0 \\
\hline Methodology & \multicolumn{2}{|c|}{$\begin{array}{l}\text { Identified the main methodologies and research } \\
\text { techniques used }\end{array}$} & 18 & 0 \\
\hline Significance & \multicolumn{2}{|c|}{$\begin{array}{l}\text { Rationalized the practical significance of the research } \\
\text { problem }\end{array}$} & 18 & 0 \\
\hline Rhetoric & \multicolumn{2}{|c|}{$\begin{array}{l}\text { Was written with a coherent, clear structure of analysis } \\
\text { that supported the review }\end{array}$} & 5 & 13 \\
\hline Type & \multicolumn{2}{|c|}{ Criterion for Evaluation of Reference Materials } & Yes & No \\
\hline & References: & 30 or more & 18 & 0 \\
\hline \multirow{2}{*}{\multicolumn{2}{|c|}{$\begin{array}{l}\text { Sources from journals, government documents, juried } \\
\text { publications, theses, dissertations, conference proceedings, } \\
\text { official reports from reputable organizations, like World } \\
\text { Economic Forum (WEF), McKinsey Global Institute (MGI), } \\
\text { Organization for Economic Cooperation and Development } \\
\text { (OECD) }\end{array}$}} & 10 to 29 & 0 & 0 \\
\hline & & Less than 10 & & 0 \\
\hline \multicolumn{3}{|c|}{ Criterion for Evaluation of Conceptual or Theoretical Framework } & Yes & No \\
\hline \multicolumn{3}{|c|}{$\begin{array}{l}\text { Theory or model is clearly defined and linked to the study. The theory is } \\
\text { explained, and it is evident how it will situate the study into the larger } \\
\text { theory. }\end{array}$} & 8 & 0 \\
\hline \multicolumn{3}{|c|}{$\begin{array}{l}\text { Theory is loosely related to the study or theoretical framework is unclear or } \\
\text { not related to the literature review or inquiry. }\end{array}$} & 9 & 0 \\
\hline \multicolumn{3}{|c|}{ There is no evidence of theory or a theoretical framework } & 1 & 0 \\
\hline
\end{tabular}




\section{Discussion}

This study found that students faced various challenges in submitting quality FYPs, as they find it difficult to engage relevant scientific literature in a comprehensive way. The main challenges are:

1) It is difficult for them to select relevant literature due to lack of knowledge of proper search and selection strategies, inability to conduct effective critical analysis of literature (especially compare and contrast of ideas), and inability to integrate suitable conceptual/theoretical framework into their own research topic.

2) They lack the proper skill to utilize these techniques effectively and, although their FYP is acceptable for a passing grade, the majority of ASs is not really convinced of their quality.

What is clear from the findings is that the students perceived that they had engaged in scientific literature in their FYPs, but the truth is that ASs did not believe they did so.

All three categories of the research participants confirmed the importance of a literature review to establish the foundation for an academic inquiry and in line with recent research (Juntunen \& Lehenkari, 2021). This is because a critical review grounded in relevant scientific literature can appropriately facilitate with critically reflecting on a research subject and testing/extending theories (Paul \& Criado, 2020). Despite the fact that there is a wide variety of information, knowledge, guidelines and recommendations on this topic, surprisingly, there is still a lack of clear understanding by students resulting in meagre quality literature reviews lacking the requisite scientific literature. Most of them produced a broadly descriptive critical literature review on the selected topic, without any critical reflection on key theories. This appears to be mainly because of students' low commitment to research and reading or a lack of motivation to conducting the research investigation on a level required for a UAS student where this academic research trend is becoming a norm. This is in line with findings from Shahsavar \& Kourepaz, (2020). It is recommended that developing a review strategy and protocol based on available guidelines is a crucial step for rigorous/critical literature reviews using relevant peer-reviewed scientific literature (Fisch \& Block, 2018; Hart, 2018; Kraus et al., 2020; Xiao \& Watson, 2019). This can help in the critical extant literature analysis on the selected FYP research topic by identifying relevant scientific theories, constructs, theoretical framework, research design and possible knowledge gaps in order to establish FYP research on a solid scientific footing (Paul \& Criado, 2020).

\section{Conclusion}

From the above findings, it can be concluded that, although students realize the importance of scientific literature in their research and writing FYPs, their knowledge was superficial and not in-depth. Although most claimed that they did read books and articles, the ASs and RMTs were not convinced that they read the books thoroughly enough to really understand and internalize the whole concept of academic research. Their opinions regarding the low quality of students' FYPs are supported by the findings in the evaluation of scientific 
literature in the FYPs, such as the lack of connection between the conceptual/theoretical framework with their own study; the lack of use of systematic strategy in sourcing and selecting of relevant articles for the research, especially in proper filtering and discarding and the lack of comparison and contrast of ideas. Through their responses to the open questions, ASs also acknowledged that students struggled with conducting a critical literature review and ended up drafting a narrative text instead of critical evaluation, analysis, or synthesis of information. Although students claimed that they did a critical analysis of relevant literature, this is not agreed upon by the majority of ASs and the findings from the analysis of the FYPs supported ASs' opinions. To overcome these challenges, various recommendations were given by ASs and RMTs, which are mentioned below.

\subsection{Limitations of the study}

In addition to widespread guidelines/recommendations on this topic, a process for engaging relevant peer-reviewed scientific literature for FYPs, especially conducted by UAS students, must be developed. The research on this topic has shown a lack of this crucial information considering the wide variety of undergraduate and post-graduate programs offered by UASs. Our study is an effort to fill this gap, thereby contributing to the research on FYPs based on scientific literature at UASs in particular.

One of the limitations of this study is the research population and the sample size. A limited number of research participants from one UAS was selected, hence the findings cannot be generalized. Due to the current pandemic situation, it was not possible to select a bigger sample. It was not easy to carry out a wider scope of the research involving more UAS due to of confidentiality and privacy issues. The findings are limited to the data collected and the framework applied, (e.g., Bootes \& Bailey, 2005; the American Public University System framework) to analyze students' FYPs. Applying other frameworks, such as those developed by Akindele (2008) or Hart (2018), may lead to different findings. Identifying the problem is only part of the story; the crucial point is finding an effective solution in this regard. For this, it is important to address the issue, as it is crucial these days for any UAS to produce high-quality FYPs. The primary responsibility lies with policy makers, ASs, RMTs and especially the final-year students to develop/refine the crucial skills for this purpose. Additionally, other stakeholders, such as curriculum design committees, HE policymakers, education advisors, FYP defense committee members, and faculty members in general, can play their parts as well.

\subsection{Research implications}

The research findings in this study demonstrated the importance of students' engagement with relevant scientific literature for their FYPs. This study provides an understanding of the perceptions of students, ASs and RMTs on the different aspects of a quality FYP. It is evident from this research that having a comprehensive knowledge and understanding of scientific literature is important on the part of students and that more effort needs to be done to ensure this. Writing an FYP is a daunting task, requiring a considerable amount 
of time, effort, knowledge and skills, therefore, students need to be better prepared before embarking on it.

Future research is needed on this topic for understanding the specific barriers for UAS students in engaging relevant scientific literature for their FYPs. Questions that might be useful in this regard may include: What exactly are the problems faced by students in conducting an effective literature review? What are the similarities and differences between new and more experienced students in conducting a scientific literature review for the FYP? How is the process of conducting a scientific literature review for a UAS different compared to a research university? We hope this important research will continue and we expect that other research in this field of study will further develop the explanation for a critical scientific literature review.

\section{References}

Aguinis, H., Ramani, R. S., \& Alabduljader, N. (2018). What you see is what you get? Enhancing methodological transparency in management research. Academy of Management Annals, 83-110.

American Public University System. (n.d.). iRubric: PADM Lit Review/Theoretical Framework Rubric. American Public University System.

Badenhorst, C. (2018). Citation practices of postgraduate students writing literature reviews. London Review of Education.

Berman, E. A. (2017). An Exploratory Sequential Mixed Methods Approach to Understanding Researchers' Data Management Practices at UVM: Integrated Findings to Develop Research Data Services. Journal of eScience Librarianshp, 6(1).

Bologna Working Group. (2005). A Framework for Qualificaitons of the European Higher Education Area. Copenhagen: Danish Ministry of Science, Technology and Innovation.

Bootes, D. N., \& Bailey, P. (2005). Scholars before researchers: On the centrality of the dissertation literature review in research preparation. Educational researcher, 34(6), 3-15.

Braun, V., \& Clarke, V. (2006). Using thematic analysis in psychology. Qualitative Research in Psychology, 3(2), 77-101.

Carracedo, F., Vilaró, J., González, J., Casas, P., Almiñana, J., Zaragoza, J., . . Samsó, M. (2018). A proposal to develop and assess professional skills in engineering final year projects. International Journal of Engineering Education, 400-413.

Chen, D.-T., Wang, Y.-M., \& Lee, W. (2016). Challenges confronting beginning researchers in conducting literature reviews. Studies in Continuing Education, 38(1), 47-60.

Chen, H. L., Chen, W. T., \& Lin, Y. L. (2016). Earned value project management: Improving the predictive power of planned value. International Journal of Project Management, 22-29.

Creswell, J. W. (2003). Research design: Qualitative, quantitative, and mixed methods approaches (2nd ed.). Sage.

Cronin, P., Ryan, F., \& Coughlan, M. (2008). Undertaking a Literature Review: A Stepby-Step Approach. British Journal of Nursing, 17(1).

Cuozzo, B., Dumay, J., Palmaccio, M., \& Lombardi, R. (2017). Intellectual capital disclosure: a structured literature review. Journal of Intellectual Capital.

Fisch, C., \& Block, J. (2018). Six tips for your (systematic) literature review in business and management research. Management Review Quarterly, 68(2018), 103-106. 
Grant, C., \& Osanloo, A. (2015). Understanding, Selecting, and Integrating A Theoretical Framework in Dissertation Research: Creating the Blueprint for Your "House". Administrative Issues Journal: Connecting Education, Practice, and Research, 4(2), 12 26.

Hart, C. (2018). Doing a Literature Review: Releasing the Research Imagination (2nd ed.). London: SAGE.

Illing, J. (2014). 2014. In W. Blackwell (Ed.), Understanding Medical Education: Evidence, Theory and Practice (pp. 331-347). The Association for the Study of Medical.

Izadinia, M. (2014). Authorship: The hidden voices of postgraduate TEFL students in Iran. Journal of Academic Ethics, 12(4), 317-331.

Jawitz, J., Shay, S., \& Moore, R. (2002). Management and assessment of final year projects in engineering. International Journal of Engineering Education, 472-478.

Juntunen, M., \& Lehenkari, M. (2021). A narrative literature review process for an academic business research thesis. Studies in higher education, 330-342.

Komba, S. C. (2015). The perceived importance of communication skills course among university students: the case of two universities in Tanzania. African Journal of Teacher Education.

Kraus, S., Breier, M., \& Dasi-Rodriguez, S. (2020). The art of crafting a systematic literature review in entrepreneurship research. International Entrepreneurship and Management Journal, 16((2020)), 1023-1042.

Lederman, N. G., \& Lederman, J. S. (2015). What is a theoretical framework? A practical answer. Springer.

Malechwanzi, J. M., Lei, H., \& Wang, L. (2016). Students' Perceptions and Faculty Measured Competencies in Higher Education. International Journal of Higher Education, 5(3), 56-69.

Mok, K. Y., Shen, G. Q., \& Yang, J. (2015). Stakeholder management studies in mega construction projects: A review and future directions. International journal of project management, 446-457.

Norton, R. E. (2019). Herder's aesthetics and the European Enlightenment. Cornell University Press.

Paul, J., \& Criado, A. (2020). The art of writing literature review: What do we know and what do we need to know? International Business Review, 29(4), 101717.

Quinlan, C. (2011). Business Research Methods (1st ed.). Hampshire: Southwestern Cengage Learning.

Randolph, J. J. (2009). A Guide to Writing the Dissertation Literature Review. Practical Assessment, Research \& Evaluation, 14(13).

Ravitch, S. M., \& Riggan, M. (2017). Reason \& rigor: How theoretical frameworks guide.

Roberts-Holmes, G. (2018). Doing your early years research project: A step by step guide. Sage.

Saunders, M. N., Lewis, P., \& Thornhill, A. (2019). Doing research in business $\mathcal{E}$ management: An essential guide to planning your project. Pearson.

Shahsavar, Z., \& Kourepaz, H. (2020). Postgraduate students' difficulties in writing their theses literature review. Cogent Education, 7(1).

Snyder, H. (2019). Literature Review as a Research Methodology: An Overview and Guidelines. Journal of Business Research, 333-339.

Sodhar, I., Noor, D., Memon, I., \& Malik, M. (2020). A survey of faced issues and challenges of undergraduate students in final year project. International Journal of Advanced Research in Engineering and Technology, 649-654.

Vereniging Hogescholen (Netherlands Association of Universities of Applied Sciences). (2019). The Professional Master Standard. Copenhagen: Vereniging Hogescholen. 
Walter, L., \& Stouck, J. (2020). Writing the Literature Review: Graduate Student Experiences. The Canadian Journal for the Scholarship of Teaching and Learning, 11(1).

Xiao, Y., \& Watson, M. (2019). Guidance on conducting a systematic literature review. Journal of Planning Education and Research, 39(1), 93-112. 